\title{
COVID-19, REMOTE TEACHING, AND THE SCHOOL ECOSYSTEM: \\ A DELICATE RELATIONSHIP
}

\author{
André Hedlund \\ andrelshedlund@gmail.com \\ Edify Education (Rio de Janeiro, Brazil)
}

\begin{abstract}
The paper explores the current situation with remote teaching in schools in Brazil from the perspective of ecological systems theory and school ecosystem. The situation is analysed from the viewpoints of the main stakeholders: children, parents, teachers and school managers. The author describes typical questions that the stakeholders raise in Brazil and offers answers. Advice is also offered on what can be done by the stakeholders to keep the ecosystem balanced.

Key words: e-learning, distance learning, remote teaching, EFL, teaching methodology, school ecosystem.

How to cite this article: Hedlund A. (2021). COVID-19, Remote Teaching, and the School Ecosystem: a Delicate Relationship. Professional Discourse \& Communication, 3(1), pp. 85-91. (in Russian). https://doi.org/10.24833/2687-0126-2021-3-1-85-91
\end{abstract}

$\mathrm{T}$ The coronavirus pandemic, with all the suffering and fear caused in the population, has been keeping kids and teens away from their schools and forcing the entire school ecosystem to rethink long-held educational practices on a never-before-seen scale. How is this affecting education and stakeholders' relationship with one another?

According to psychologist Urie Bronfenbrenner [Ettekal \& Mahoney, 2017], we can look at human development as a series of relationships that take place in and are affected by not only the immediate surroundings, but also outer circles, which represent incrementally more distant environments or contexts that form an ecological system.

What happens in all those concentric circles can impact what happens on the individual level? We could say that on the microsystem level, schools and homes have been directly affected by mass media reports of COVID-19 [Hedlund, 2020a], which belong to the ecosystem level and by shared cultural values and beliefs of how we should deal with the pandemic (on the macrosystem level).

For our analysis, let's focus on the microsystem, mesosystem and exosystem levels. They respectively refer to the level of the student's immediate surroundings (school and family), the level where these surroundings communicate, and the level where the student is not inserted, such as family workplace. 
First let's think about the context of each stakeholder directly affected by the lack of face-toface classes:

Children and adolescents: This group has been forced into confinement right in the middle of motor, socioemotional, and cognitive development. Many are frustrated with the demands, suffering with anxiety and confused about what is really happening. Some of them need to deal with loss and grief due to the death toll of this crisis.

Parents: Many parents have forcibly transitioned to remote working and need to cope with the demands of their jobs while juggling with the needs of their family. Suddenly, parents are required to to be present more than ever to support their children during online classes and when carrying out their activities.

Teachers: To keep the course up and running and, especially, the contact with the children, teachers have been working harder than ever and around the clock to incorporate new skills (such as recording videos and teaching remotely) and to create high quality lessons and materials that help keep the children engaged and allow them to work as independently as possible

School managers: From putting together entire CPD [Hedlund, 2017] programs on online teaching overnight and purchasing digital tools/services to solving financial problems due to the high dropout rates, managers have been struggling to keep their doors open.

Bear in mind that I am not even considering so many others who have lost their jobs, do not have good quality internet access and do not even have more than one or two digital devices at home. For these, the reality is a million times harsher.

This incredibly tense scenario can become the perfect storm in many educational settings. It is perfectly natural and expected that everyone feels under enormous pressure. The problem is when this pressure is neglected or poorly managed and the fundamental role of education is undermined. What is missing in this ecosystem sustained by a delicate balance of stakeholders' needs and expectations?

\section{EVERYONE NEEDS TO HAVE PATIENCE AND EMPATHY}

UNESCO has set up a COVID-19 Global Monitoring page that has been collecting data on a daily basis about school closure since mid-February [Education: From disruption to recovery, 2021]. From the third week of March until today, hundreds of millions of the world's students have been away from their schools. From April to the beginning of June, 1 billion or more children and teenagers were out of their schools. In April, specifically, 1.5 billion students, which corresponds to $90 \%$ of enrollments in the world, were affected by school closure. This means that the entire ecosystem had to mobilize resources and create procedures overnight to meet a huge demand that did not exist before.

What does this mean in practical terms? It means that a very large number of teachers had to learn to use online tools to make content available asynchronously (which normally means prerecording things), in addition to time to connect with their students synchronously. This is quite the challenge and requires huge amounts of energy and hard work from everyone. Many do not feel comfortable in front of the camera and / or with the constant surveillance of families that often criticize some practices without any pedagogical or linguistic grounds. Remember that criticism has to be specific and constructive to help improve things. It is extremely exhausting to prepare for your work knowing that, regardless of how much effort you put into trying to achieve the best results, many will complain about aspects that are beyond your control. 
The truth is that the pressure on schools with unattainable demands creates a harmful environment, which affects the mental health of everyone involved. Teachers are exhausted, families do not have time to help their children and often demand different solutions for the school (some want more activities, others want less study, some want bilingual classes given almost exclusively in the student's first language (L1), others want greater exposure to English). At the same time, managers try to offer what is possible and children and adolescents suffer from mental confusion, excessive demands and lack of social contact and affection.

\section{WE MUST ADJUST EXPECTATIONS}

It is worth remembering that what we are experiencing is best described as remote emergency teaching than anything else. Although many of us have been teaching online for more than 5 months, there was no structure for this demand and no one had been properly trained. A substantial change and transition to this type of teaching demands time and investment. Therefore, much of what schools and teachers are doing is what is currently feasible and possible within our human capabilities. That means we need to reflect on what is achievable, desirable and what isn't.

Since I work as a bilingual program mentor, here are some practical examples of questions and demands stakeholders might have based on my experience:

\section{The school should keep the same workload as the face-to-face classes because parents continue to pay the same.}

In fact, we need to understand that remote teaching is not the same and, therefore, cannot replicate much of what happens inside the classroom. A face-to-face class has moments of classroom management, sharing and interaction with colleagues, games and movement. All of this takes time. Dynamic activities engage children and are difficult and sometimes impossible to reproduce remotely. In addition, very long videos and / or recorded classes are exhausting and ineffective for children and adolescents. Neuroscience shows that the brains of children and adolescents have difficulty in controlling their impulses, their focus and their emotions. On the other hand, maintenance of the schools' facilities is very costly and schools are saving money in that regard. Nevertheless, as I mentioned before, most schools are struggling with financial problems because of excessive dropout levels particularly concerning Very Young Learners

\section{Families find teachers' teaching skills below the required levels}

This topic is extremely sensitive and demands great caution. Many parents, with the best intentions, end up judging the quality of teachers negatively due to several factors. They confuse pronunciation with accent, use specific and punctual factors they do not know much about to criticize teaching skills and generalize to the whole class. Does this mean that teachers are exempt from failure? Of course not. Just like any professional in any field, there are aspects of English teaching professionals, chiefly in a bilingual program, that require practice and improvement. There are teachers who have a lot to learn and others who have learned a lot about a certain subject or competency. However, it is necessary to discuss in community, involving all stakeholders, what is possible to do now. Would a sudden change (such as replacing a teacher) be the best solution in a time of difficulties like this? Is what families demand really supported by pedagogical and scientific theories and practices that concern English Language Learning and bi- 
lingualism? We need to understand that professional development (teaching skills and linguistics) is a process and that we have to encourage the professional and not disqualify them, especially at this time.

\section{The technical quality of the lessons is low}

Children born in the 2000s belong to Generation $\mathrm{Z}$ and those born from 2010 to Generation Alpha. Unlike adults born in the 70s and 80s (and until the early 90s), digital technology is part of everyday life and works as body extensions of kids and teens in these new generations. Devices such as cell phones, tablets and things such as internet access, videos and video games create one of the foundations of children's reality in kindergarten and elementary school. In this context, it is natural for children to judge videos created by teachers as low quality materials. Dissatisfaction often comes from themselves or may reflect the projections of their parents. Remember that many teachers do not have cutting-edge video recording equipment. Many don't know how to work with image editing and audio capturing. Most teachers do not even have a proper microphone, tripod or support for the camera, an adequate space for recording, with silence and good lighting, among many other things.

\section{EVERYONE NEEDS TO UNDERSTAND AND FACILITATE THE PROCESS}

How long does a 10-minute video produced by a teacher need to get to the platform on which the child can access? Between recording and re-recording, interrupting because of noise and resuming filming, editing, rendering the video, uploading to the drive, sending it to the coordinator or mentor for feedback, getting back with comments, having to redo some parts and repeat all process to finally share the link on the platform, add the description and purpose of the video, the average time spent for a video of this size can be 6 to 15 times more than the video itself. That means countless hours of work at the end of the day.

This issue is a practical example of how often people are unaware of the different steps required in the process when they simply focus on the final product. Let's understand other frequently asked questions about the processes of an English Language class or a bilingual program:

\section{Teachers need to speak $L 1$ so that parents could understand and help their children}

The central purpose of a bilingual program is to offer greater exposure to the additional language (English, in our case) so that students are immersed in that language. This means a higher workload compared to regular English classes and that the main means of communication during classes is English. When parents demand that teachers use more L1 than English, they end up interfering negatively with the most fundamental pillar of the program. It is essential to understand that students should not be helped at every step of the learning process. Many parents are frustrated when their children say they don't understand anything and think their intervention will help. The cost of this "aid" can be quality reduction and loss of purpose of a bilingual program. Ultimately, even though there are difficulties along the way, children acquire the additional language naturally and incrementally.

\section{Children are not learning anything or making progress}

Both the process of acquiring and learning a language takes time. Years according to the Common European Framework of Reference (CEFR) [Knight, 2018]. Younger children in Early 
Years Education need to review the content countless times to consolidate knowledge in the brain. Lesson that may seem extremely repetitive and playful have a clear pedagogical purpose based on academic studies and references in education. For those who wish to understand a little more of the theoretical-scientific basis, I recommend doing research about the concepts proposed by Jean Piaget, Loris Malaguzzi, Maria Montessori, Lev Vygotsky and Jerome Bruner. An example of a common misconception is the perception that the child cannot produce the words orally, hence, the child is not learning. Lack of oral production does not mean the child wasn't able to understand the words uttered by the teacher or the grammatical structures utilized. Demonstrating comprehension, intention and action during the lesson is evidence that shows teachers that children are on the right track.

\section{All classes should be synchronous (live classes)}

Synchronous classes have their purpose and should have their space. It is the moment in which teachers are able to establish a greater emotional bond with children, ensure more interaction and respond more effectively to the demands and stimuli provided by students in real time. However, synchronous classes do not allow several equally important features to take place. Synchronous classes depend a lot on the quality of the connection, which usually means lower video and audio resolution, they require greater proximity to the teacher's screen, which can make it difficult for the teacher to create playful scenarios and to use body language effectively. Synchronous lessons also promote a great sense of sameness. With asynchronous classes, teachers can edit videos, add effects, shoot in different places in the house and use objects more easily, they can better fit their entire body on the screen (instead of just the shoulders, neck and head, as in synchronous class) and can use lots of body language to convey meaning. The recorded lessons give more flexibility to everyone involved. If students, for whatever reason, are unable to attend at a certain time, it is possible to attend classes at another time. It is also possible to pause and review as many times as necessary, which creates an important feature of differentiation and individualization. Ideally, both synchronous and asynchronous lessons should be combined.

\section{HOW CAN THE STAKEHOLDERS OF THIS DELICATE ECOSYSTEM WORK TOGETHER?}

After the issues raised above, after all, what is the role of the family, students, managers, and teachers? I believe it is about learning and conciliation. The understanding that every stakeholder's involvement is essential for the success of the school ecosystem needs to be focus. Family can and should demand certain things from schools and teachers, but those demands should be grounded and take into consideration the role they play in the learning process of their children. What does that mean?

Families, do not criticize everything that schools are offering without knowing exactly how the processes work. Talk in a friendly and constructive way to managers and, especially, teachers to reach a consensus. Make your demands to help and remember everyone's moment and monumental effort.

Do not interfere too much with your children's class. Remember that they need to build knowledge and create more autonomy. Do not give them answers during the lessons! The important thing is not to always get it right, but to learn. 
Managers and teachers, understand the role of synchronous (live) and also asynchronous (recorded) classes. Both moments are important. Learn more about active methodologies, playfulness, bilingualism, CLIL, emotional intelligence, mindfulness and design thinking [Darn, 2020]. These concepts can give you broader view of what modern teaching encompasses.

Students, be helpful and patient. We understand how much you're suffering and we want this to be over soon. Remember that just because you do not like a lesson or you feel that it is not "fun" enough for you, that doesn't mean you don't have to study and respect your teachers. Not everything is fun in life and you need to learn how to deal with frustration and responsibility.

The moment is challenging and causing a lot of suffering, no doubt. However, despite all possible damage to education (and they will exist), perhaps we should focus on the how and why of education rather than the what. Instead of demanding the replication of outdated educational models, based on a particular perception of what teaching English as a whole should be, stakeholders can take advantage of this open wound to study more what successful educational systems do, which pedagogical perspectives they propose, what approach, methodology and techniques they favor.

Everyone needs to understand the reason for the longer exposure to the additional language, the role teaching in the additional language instead of about it and the place of routines and playfulness in the learning process of children and so on. If our focus is always on content and how much of it was lost in this period, we will lose the opportunity to rethink the form and rationale of education. We will lose the opportunity to rethink the place of ethics, emotional intelligence, learning to learn, developing competencies that are necessary for the job market and, above all, promoting a healthy relationship between body and mind.

Remember the following: content changes with an impressive speed and is increasingly available on different media and platforms. What is in short supply is not the content, but rather what to do with this content to transform it into knowledge, which generates skills, which, over time, will create competencies. The most noble product of education is the possibility of transforming the individual and their ability to adapt to challenges that don't even exist yet. Education in my country is flawed and has produced very low results in national and international rankings [Hedlund, 2020b]. With the fracture exposed in our educational system, now is the time for unity and conciliation between parents, managers, students and teachers. We need to rethink our relationship, understand the complexities and defend our most precious asset if we are to survive the pandemic with as little damage as possible and, in fact, begin to transform education.

My final message is that, as Urie Bronfenbrenner suggests, the links and impact caused by each of the circles in the ecologic systems theory can have lasting effects on the individual level of human development. I don't want to be a hypocrite and claim that everything will be OK. I see teachers suffering to cope with the new demands, managers pushing for schools to reopen out of desperation, children suffering psychological and physical abuse at home and families trying to make ends meeting without a job. But as stakeholders of this ecosystem, we must come together and do our best to minimize the negative consequences that might only arise many years in the future. Our kids and teens need to be spared of traumas that can scar them for life. Let's all reflect on our roles, rethink our attitudes and hope for the best. 


\section{REFERENCES}

1. Darn, S. (2020). CLIL: A lesson framework. Retrieved from https://www.teachingenglish.org.uk/ article/clil-a-lesson-framework (accessed: March 10, 2021).

2. Education: From disruption to recovery. (2021). Retrieved from https://en.unesco.org/covid19/ educationresponse (accessed: March 10, 2021).

3. Ettekal, A., \& Mahoney, J. (2017). Ecological systems theory. In K. Peppler (Ed.), The SAGE encyclopedia of out-of-school learning (Vol. 1, pp. 239-241). SAGE Publications, Inc., https://www. doi.org/10.4135/9781483385198.n94

4. Hedlund, A. (2017). Sharing to multiply: the unbeatable old formula of life, and just about anything, including Continuing Professional Development (CPD). Retrieved from https://edcrocks. com/2017/05/23/sharing-to-multiply-the-unbeatable-old-formula-of-life-and-just-about-anything-including-continued-professional-development-cpd/ (accessed: March 10, 2021).

5. Hedlund, A. (2020a). 6 Things the Coronavirus lockdown made me realize. Retrieved from https:// edcrocks.com/2020/03/21/6-things-the-coronavirus-lockdown-made-me-realize/ (accessed: March 10, 2021).

6. Hedlund, A. (2020b). The Brazilian Education Fracture and COVID-19: A Historical Perspective. Retrieved from https://policybristol.blogs.bris.ac.uk/2020/08/24/the-brazilian-education-fracture-and-covid-19-a-historical-perspective/ (accessed: March 10, 2021).

7. Knight, B. (2018). How long does it take to learn a language? Retrieved from https://www.cambridge.org/elt/blog/2018/10/11/how-long-learn-language/ (accessed: March 10, 2021). 